\title{
NOTATÉCNICA
}

\section{A CARTOGRAFIA GEOMORFOLÓGICA APLICADA A ESTUDOS DE INTEGRIDADE ECOLÓGICA EM CURSOS D'ÁGUA DE REGIÕES DE CABECEIRA}

\author{
Cláudio Eduardo Lana \\ Universidade Federal do Espírito Santo - Departamento de Engenharia Rural \\ CCA-UFES, Depto de Eng. Rural, Guararema, Alegre - ES, Cep 29.500-000. Tel.: 28-3552-8952 \\ claudiolana@degeo.ufop.br \\ Paulo de Tarso Amorim Castro \\ Universidade Federal de Ouro Preto - Departamento de Geologia \\ Campus Morro do Cruzeiro, S/N, Ouro Preto - MG, Cep 35.400-000. Tel.: 31-3559-1600 \\ paulo_de_tarso@degeo.ufop.br
}

\begin{abstract}
Resumo
O presente trabalho versa sobre a elaboração de mapas geomorfológicos integrados, como uma base para a realização de estudos sobre a integridade ecológica de rios de regiões montanhosas. Esse tipo de mapeamento, além de servir de parâmetro para análises de expectativa de impacto, é útil também nos casos em que estudos de monitoramento futuros são necessários. Para tanto, é proposta uma metodologia cartográfica de alta precisão e baixo custo, embasada em um estudo de caso, no qual são apresentados dois mapas de segmentos de drenagem fluvial no alto curso do rio das Velhas (MG), em escalas de alta resolução (1:400). O posicionamento dos pontos de coleta, bem como a discriminação dos diferentes habitats, sob o ponto de vista físico, estão presentes nos mapas confeccionados. A cartografia integrada se constitui num denominador comum em busca da padronização de linguagem e facilitação do acesso aos produtos de todas as pesquisas, conforme prescrito pelo estágio mais completo da abordagem científica com múltiplos enfoques, que é a transdisciplinaridade.
\end{abstract}

Palavras chaves: geomorfologia de rios, cartografia, interdisciplinaridade.

\begin{abstract}
This paper presents the importance of geomorphologic mapping as a base of ecological integrity studies in mountain region rivers. This kind of mapping can be used as a tool to impact analysis before and after building constructions. Here is proposed a high resolution and low cost cartographic methodology whit two examples, that are two maps of fluvial segments of Velhas river (Minas Gerais State). Both were generated in high resolution scale (1:400). The position of their studied points and the separation of different physical habitats are presented on these two maps. The integrated cartography is a central point to standardize the scientific language and make easy the access to the research products, as according to the transdisciplinarity paradigm.
\end{abstract}

Keywords: river geomorphology, cartography, interdisciplinarity.

\section{Introdução}

O paradigma interdisciplinar criado na França e difundido pelo mundo a partir da década de 60 (Silva, 1999) tem influenciado cada vez mais as formas de abordagem das questões ligadas ao meio ambiente, promovendo uma interação crescente entre as ciências naturais.

No caso específico das obras de engenharia, por exemplo, tanto a cartografia, quanto a integração dos resultados de pesquisas ambientais diversas são de suma 
importância para os estudos preditivos e projetivos dos impactos advindos dos mais variados empreendimentos.

O ato de cartografar, de acordo com Gilvear (1999), permite conhecer a correta situação da geomorfologia préempreendimento, da mesma forma que proporciona uma sólida base para estudos de impacto e monitoramentos pósempreendimento.

Em alguns casos é comum se observar um caráter reducionista nas metodologias aplicadas. Por exemplo, em estudos do sistema fluvial, o substrato é freqüentemente considerado como uma plataforma literalmente inerte, estável e homogênea, fato que não está em concordância com os conceitos geomorfológicos modernos, principalmente os ligados à tectônica cenozóica e ambientes deposicionais recentes.

Nos casos em que os estudos ambientais envolvem registro cartográfico, percebe-se que as feições geomorfológicas levadas em consideração são apenas aquelas originadas em ambientes de retenção de sedimentos, como, por exemplo, as barras arenosas. Além disso, boa parte desses trabalhos se concentra nas porções sob a lâmina d'água, ao contrário das proposições de Ward (2002).

Ward (op. cit.) acredita que a superfície ou paisagem fluvial é um termo que diz respeito a uma visão mais geral, onde deva ser levada em consideração uma extensa série interconectada de biótopos e gradientes de energia os quais, juntamente com a comunidade biótica, constituem o sistema fluvial.

Pesquisadores como Barbour et al. (1999) têm enfatizado a relação íntima entre o habitat e a diversidade biológica. No entanto, os trabalhos ecológicos raramente posicionam com precisão os seus dados no espaço e esse fato ocasiona uma perda da real dimensão dos habitats considerados, bem como de seu posicionamento absoluto ou até mesmo relativo. Nesse contexto, o desenvolvimento e adaptação de metodologias cartográficas aplicáveis ao estudo geomorfológico de ecossistemas fluviais é uma tarefa de grande valia.

Castro et al. (2003) consideram que a afirmação de Barbour et al. (1999) permite assumir que o reconhecimento da qualidade do habitat, sobretudo os atributos geomorfológicos do meio, é crítico para qualquer avaliação do nivel de preservação de segmentos fluviais. No contexto rio - paisagem, a representação desses atributos em escala pontual mostra-se como uma ferramenta adequada e dá suporte às interpretações das distintas estruturas do ambiente físico, em especial nos estudos ambientais integrados.

Neste trabalho é apresentado um estudo cartográfico de detalhe efetuado sobre dois segmentos de rios, distintos tanto em termos de degradação, quanto de constituição geomorfológica (geologia e sedimentologia) e, conseqüentemente, ecológica. Para tanto, foram adotados segmentos que integram o conjunto pesquisado por Lana (2004), pertencentes à bacia do alto rio das Velhas.

Este trabalho tem como objetivos:

- descrever sucintamente os passos adotados para cartografia planimétrica de alta resolução da geomorfologia e outros aspectos ambientais em segmentos fluviais montanhosos, utilizando metodologias de baixo custo e alta praticidade de uso (prancheta \& alidade e trena \& bússola); - realizar a integração cartográfica dos pontos de coleta de quatro projetos de pós-graduação com ênfases distintas realizados nos mesmos segmentos;

- apresentar o resultado cartográfico de dois segmentos fluviais com geomorfologia, dinâmica sedimentológica e pressão antrópica diferentes e

- posicionar nas cartas os locais de coleta adotados em cada um dos quatro projetos citados acima.

\section{Localização da área de estudo}

A bacia do rio das Velhas está localizada na região central do Estado de Minas Gerais, aproximadamente entre as latitudes $17^{\circ} 15^{\prime}$ e $20^{\circ} 25^{\prime}$ 'S e longitudes $43^{\circ} 25^{\prime}$ 'e $44^{\circ} 50^{\prime}$ 'W.

Os trabalhos foram realizados no alto curso dessa bacia, que drena os territórios que compreendem as proximidades da zona urbana de Ouro Preto e os municípios de Sabará, Belo Horizonte, Contagem e Caeté, limitando-se a norte pelas serras da Piedade, Curral e Taquaril.

Os segmentos adotados neste trabalho apresentamse em posições e dinâmicas de fluxo distintas dentro da bacia. O segmento 1 encontra-se próximo à cabeceira, mas apresenta uma dinâmica sedimentar deposicional, comprovada pelas feições geomorfológicas presentes. O segmento 2 está posicionado numa porção mais à jusante, no entanto, apresenta uma dinâmica erosiva, evidenciada pelas características observadas no leito.

\section{Metodologia}

\section{a) Etapa de Revisão, Testes e Padronização de Procedimentos}

Para viabilizar essa etapa, foi feito um levantamento a respeito dos principais métodos de cartografia direta existentes e de baixo custo. Essa tarefa permitiu concluir que os métodos mais indicados para a cartografia de segmentos fluviais em escala de detalhe seriam o da trena \& bússola e/ ou o da prancheta \& alidade (Lana \& Castro, 2003a).

Os métodos cartográficos mais modernos e mais caros (estação total e, sobretudo, GPS geodésico) não foram utilizados neste trabalho. A proposta é tornar os levantamentos cartográficos mais acessiveis, independentemente da área de formação dos profissionais e 
da disponibilidade de recursos financeiros.

De acordo com relatos da literatura especializada (p. ex.: Lahee, 1952; Low, 1957; Compton, 1962 e 1985), nos métodos da trena \& bússola e da prancheta \& alidade, os erros nominais são inferiores a $0,1 \%$. No entanto, o método da prancheta \& alidade possui uma grande vantagem em relação ao da trena \& bússola, que é o fato do mapa ser traçado diretamente no campo, sem a necessidade de interpolações em escritório. Além disso, ele permite que dados da altimetria dos pontos também sejam obtidos.

Apesar de ser o mais indicado, o método da prancheta $\&$ alidade passou por uma bateria de testes no campo em um segmento do ribeirão Silva, também pertencente à bacia do rio das Velhas, escolhido aleatoriamente para esse fim (Lana \& Castro, 2003b). Os resultados desses testes foram satisfatórios, tendo sido discriminadas, com boa resolução, diversas feições geomorfológicas nas áreas externas e internas do canal, como barras marginais e internas, porções da planície de inundação e uma pequena drenagem tributária. Dessa forma, o método da prancheta $\&$ alidade foi adotado como método principal a ser utilizado nos levantamentos.

A partir da etapa de revisões e testes, estabeleceramse os métodos para a execução dos levantamentos cartográficos propriamente ditos:

- método da irradiação, no qual o ponto inicial sobre o qual o equipamento é montado, se situa numa região central em relação aos pontos que devem constar do mapa;

- método da resseção (cutting in), em que o ponto sobre o qual se fixa o aparelho, além de ser um ponto de interesse para o mapeamento, é uma das extremidades da área a ser cartografada e

- método da progressão (transversing), indicado para feições onde uma das dimensões é consideravelmente maior que as demais (geralmente, feições compridas) e onde a fixação dos aparelhos numa posição central é impossível ou desaconselhável. Consiste no registro de um ponto a partir do ponto inicial e imediata mudança de estação, sendo essa nova estação o último ponto cartografado na estação anterior e assim por diante.

Como se trata de um método onde há várias mudanças de estação, o erro pode ser acumulado e isso pode prejudicar o resultado final. É por isso que se utiliza o recurso das visadas à ré para certificar a não ocorrência de erros advindos das mudanças de estação.

Cada um dos métodos é adotado nas condições em que for mais conveniente e sua aplicação, em certos casos, é feita em associação com os demais métodos descritos.

As principais dificuldades dessa etapa estão relacionadas ao acesso às feições internas (margens muito íngremes, densamente vegetadas ou escorregadias) e às externas (vegetação densa, perigos de atolamento, etc.), poluição da água e rịscos de contaminação biológica e/ou química, profundidade da lâmina d'água, energia do fluxo d'água nas corredeiras.

\section{b) Adaptações dos Procedimentos Cartográficos}

Há casos em que a alidade é incapaz de visar determinados pontos interessantes para o mapeamento. Nesses casos, é necessário elaborar adaptações do método de cartografia para que informações importantes não sejam perdidas ou omitidas.

Com base na alta resolução e facilidade de uso, sugerese a adoção da trena e bússola como método alternativo de registro de alguns pontos. O método consiste em se registrar com a alidade o ponto que esteja mais próximo daquele não alcançado pela visada do aparelho. Feito isso, é medida a distância que esse ponto se encontra do ponto de interesse e o azimute da reta que os une. Essas informações são anotadas e passadas para o mapa final posteriormente, na fase de escritório.

\section{c) Etapa de Digitalização dos Mapas sem Uso de Mesa Digitalizadora}

Os mapas chegam do campo traçados a lápis em um papel branco e, caso necessitem de complementos à trena $e$ bússola, esses dados são passados a limpo antes do início da digitalização.

Em primeiro lugar, traça-se em cada um dos mapas um reticulado de linhas perpendiculares entre si, com a intenção de viabilizar a sua montagem em meio digital, caso tenham que ser capturados por meio de um scanner, em aparelhos pequenos, parte a parte.

Para evitar a ocorrência de outras distorções, os mapas em papel são esticados ao máximo sobre o scanner, de forma a minimizar o efeito das dobras ou amassados.

Os mapas são capturados na íntegra e salvos em formato JPEG. Na seqüência, para mapas digitalizados em várias partes, eles são adequadamente montados em programas gráficos do tipo Draw. Os arquivos finais são salvos em formato $T I F F$ e as imagens raster são importadas por programas do tipo CAD.

Os mapas são digitalizados sobre o arquivo base. Cada feição diferente é digitalizada em um layer distinto.

\section{Resultados e Discussões}

Os mapas ambientais obtidos para os segmentos 1 e 2 são apresentados a seguir. Neles podem ser vistos, além das feições geomorfológicas e aquelas derivadas da ação antrópica, os pontos de coleta de material para os demais projetos realizados nesses mesmos segmentos (Figuras $1 \mathrm{e}$ 2). 


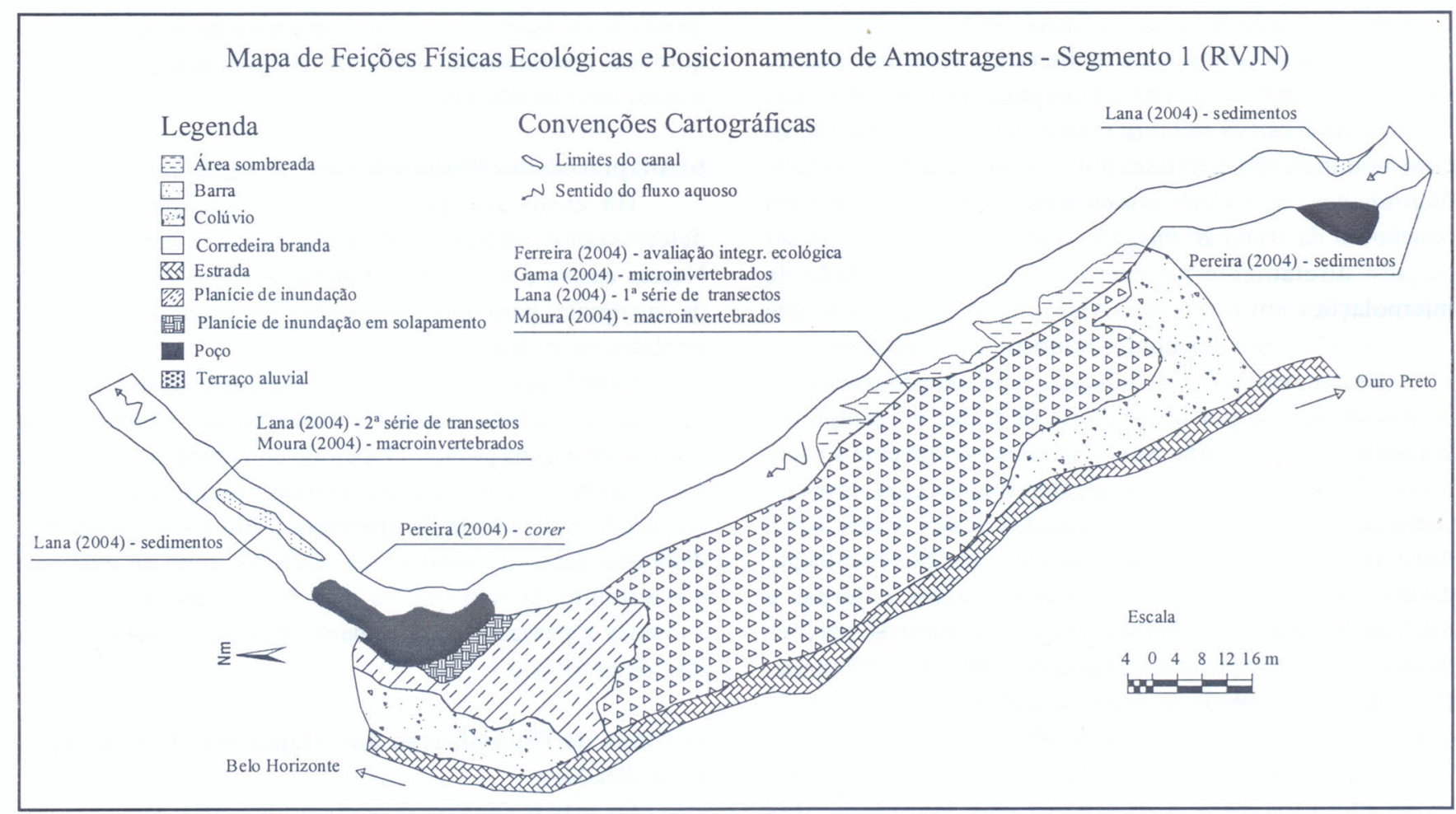

Figura 1 - Mapa ambiental de alta resolução do segmento 1, nas cabeceiras do rio das Velhas. Nele estão posicionadas as feições internas e externas do sistema fluvial, bem como os pontos e o tipo de coleta das pesquisas desenvolvidas na área atualmente. A escala original de levantamento é 1:400.

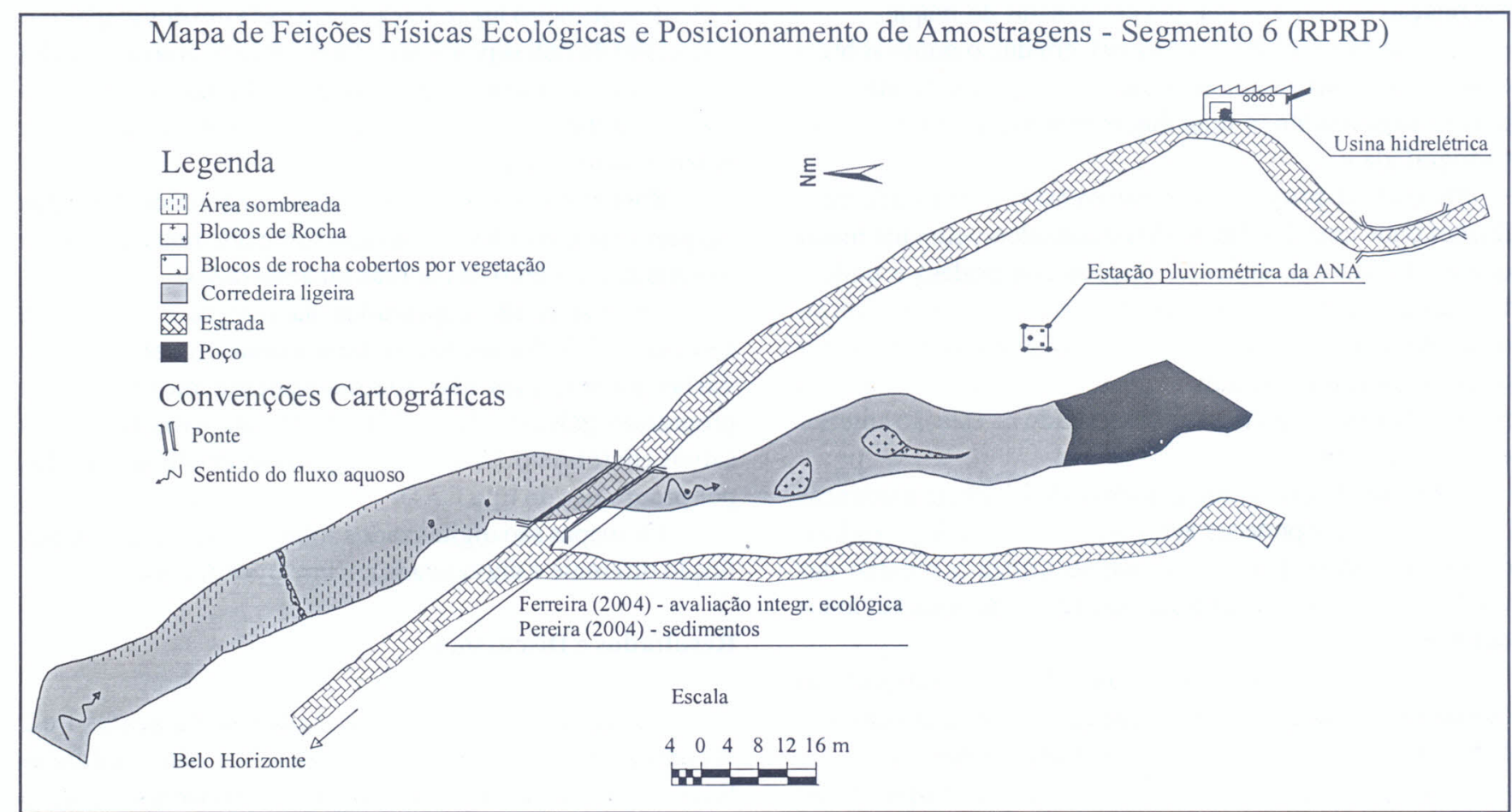

Figura 2 - Mapa ambiental de alta resolução do segmento 2, no ribeirão Capitão da Mata, afluente do rio das Velhas. Nele estão posicionadas as feições internas e externas do sistema fluvial, bem como os pontos e o tipo de coleta das pesquisas desenvolvidas na área atualmente. A escala original de levantamento é 1:400. 
O método da prancheta \& alidade é capaz de efetuar o registro de feições ecológicas com uma boa margem de detalhe e nitidez. Conseqüentemente, a cartografia ambiental realizada por meio desse método pode agregar informações importantes aos trabalhos sobre integridade ambiental, uma vez que é capaz de somar informações de origens diversas numa única base gráfica acessível a profissionais de várias áreas do conhecimento científico.

As principais vantagens do método aqui adotado em relação a alguns outros disponíveis no mercado são:

- O baixo custo, quando comparado ao dos métodos indiretos de cartografia por meio de sensoriamento remoto, nos quais as imagens com definição comparável aos mapas obtidos com o método da prancheta \& alidade são de difícil acesso e custo elevado;

- a facilidade de operação e a praticidade, quando comparado ao teodolito, pois o mapeamento com prancheta é capaz de gerar um produto gráfico ainda no campo, incluindo os dados de altimetria, quando esses se fazem necessários e - o baixo custo quando comparado a métodos digitais mais recentes como o GPS geodésico e a estação total.

A principal deficiência do método é a definição dos limites corretos de áreas muito dinâmicas, como os limites de leitos sob o efeito de ondas com grandes comprimentos de onda, pois o método registra apenas um ponto por vez e a escolha de um ponto intermediário nessas circunstâncias é uma atividade relativamente complexa.

Esse tipo de cartografia tem uma característica peculiar que é o fato de levar em consideração feições de ambientes fluviais erosivos (Figura 2), ao contrário de outras ferramentas onde a terminologia e os métodos estão adaptados somente às situações comumente observadas nos ambientes deposicionais (Figura 1). Esse é um fato importante para as regiões de cabeceira onde os segmentos erosivos são bastante comuns.

Um outro fato notável é a possibilidade de se efetuarem monitoramentos a partir desses serviços cartográficos, já que as obras civis também são registradas com nitidez, como por exemplo as estradas de rodagem das Figuras 1 e 2 e as pontes e casa de força da Figura 2.

O método de cartografia apresentado está coerente com a proposição de Roy et al. (2003), uma vez que mantém o padrão de qualidade da representação independente do nível da influência antrópica sofrida pelo segmento (o segmento representado na Figura 2 encontra-se muito mais influenciado pelas obras de engenharia que o da Figura 1).

\section{Conclusões}

A geração integrada das cartas apresentadas incorporou uma linguagem interdisciplinar aos estudos de ecologia de rios e isso se constitui numa base para a elaboração de novos trabalhos, padronizando cada vez mais a linguagem e os procedimentos cartográficos.

A cartografia de alta resolução de ecossistemas fluviais no Alto Rio das Velhas executada por meio de métodos tradicionais de cartografia direta (em contato direto com o objeto de estudo) discrimina de forma detalhada as feições geomorfológicas internas e externas dos rios estudados, fornecendo informações ecologicamente mais aplicáveis que as comumente observadas onde o detalhamento máximo atingido são apenas os limites do leito. Essa colocação é corroborada teoricamente por alguns relatos bibliográficos (p. ex.: Wiens, 2002).

É possivel que os mapas geomorfológicos e ambientais integrados, em escalas de alta resolução, representem uma inovação no que diz respeito aos métodos de investigação das questões ambientais fluviais, principalmente no que concerne à interdisciplinaridade.

\section{Referências Bibliográficas}

Barbour M. T., Gerristsen, J., Synder, B. D., Stribling, J. B. Rapid bioassessment protocols for use in streams and wadeable rivers: periphyton, benthic macroinvertebrates and fish. US. D.C., EPA 841 B-99-002, $2^{\mathrm{a}}$ Ed., Chapter 5. 1999.

Castro, P. T. A., Lana, C. E., Ferreira, H. L. M. A importância do registro das estruturas físicas de segmentos e trechos fluviais em estudos dos ecossistemas lóticos. In: IX Congresso Brasileiro de Limnologia, Juiz de Fora, 2003. Anais. № 219, 2003.

Compton, R. R. Manual of Field Geology. USA, John Wiley \& Sons, Inc, 1962. 378 p.

Compton, R. R. Geology in the Field. USA, John Wiley \& Sons, Inc, 1985.398 p.

Gilvear, D. J. Fluvial Geomorphology and river engineering: futures roles utilizing a fluvial hydrosystems framework. Geomorphology, v. 31, p. 229-245. 1999.

Ferreira, H. L. M. Relação entre Fatores Sedimentológicos e Geomorfológicos de Trechos do Alto Rio das Velhas e Mudanças Estruturais na Biota Aquática. Departamento de Geologia, Escola de Minas, Universidade Federal de Ouro Preto, Dissertação de Mestrado (em andamento), 2004.

Gama, F. O. Influência de diferentes tipos de substrato na estrutura da comunidade de microinvertebrados em ambientes fluviais no alto curso da bacia do rio das Velhas. Departamento de Geologia, Escola de Minas, Universidade Federal de Ouro Preto, Dissertação de Mestrado (em andamento). 2004. 
Lana, C. E. Cartografia Integrada de Ecossistemas Lóticos (Fluviais) no Alto Curso do Rio das Velhas MG.Departamento de Geologia, Escola de Minas, Universidade Federal de Ouro Preto, Ouro Preto, Dissertação de Mestrado. 2004. 185 p.

Lana, C. E. \& Castro, P. T. A. (a). Análise dos Métodos de Registro do Meio Físico Fluvial em Estudos Integrados do Ecossistema Fluvial. In: IX Congresso Brasileiro de Limnologia, Juiz de Fora, 2003. Anais. $n^{\circ} 553,2003$.

Lana, C. E. \& Castro, P. T. A. (b). Utilização dos Métodos de Cartografia no Levantamento de Estruturas Físicas em Escala de Detalhe em Ecossistemas Fluviais. In: IX Congresso Brasileiro de Limnologia, Juiz de Fora, 2003. Anais. $\mathrm{n}^{\circ}$ 542, 2003

Lahee, F. H. Field Geology. USA. McGraw-Hill Book Company, Inc, 1952.883 p.

Low, J. W. Geologic Field Methods. USA. Harper \& Brothers, $1957.489 \mathrm{p}$.

Moura, M. A. Influência do tipo de substrato e do grau de sombreamento da vegetação ripária sobre a comunidade de macroinvertebrados bentônicos em ambientes de poços e corredeiras do alto curso do rio das Velhas. Departamento de Geologia,
Escola de Minas, Universidade Federal de Ouro Preto, Dissertação de Mestrado (em andamento). 2004.

Pereira, J. C. Avaliação da mobilidade e biodisponibilidade de metais-traço em sedimentos de superfície da bacia do alto rio das Velhas. Departamento de Geologia, Escola de Minas, Universidade Federal de Ouro Preto, Ouro Preto, Tese de Doutoramento (em andamento). 2004.

Roy, A. H., Rosemond, A. D., Paul, M. J., Leigh, D. S., Wallace, J. B. Stream macroinvertebrate response to catchment urbanization (Georgia, U.S.A.). Freshwater Biology, v. 48, p. 329-346. 2003.

Silva, D. J. O paradigma transdisciplinar: uma perspectiva metodológica para a pesquisa ambiental. In: Workshop sobre interdisciplinaridade, INPE - São José dos Campos, 1999. Artigo na íntegra, 30 p., 1999.

Ward, J. V. Riverine landscapes: biodiversity patterns, disturbance regimes, and aquatic conservation. Biological Conservation, v. 83, p. 269-278. 1998.

Wiens, J. A. Riverine landscapes: taking landscape ecology into the water. Freshwater Biology, v. 47, p. 501515.2002 